Available online at http://docs.lib.purdue.edu/jate

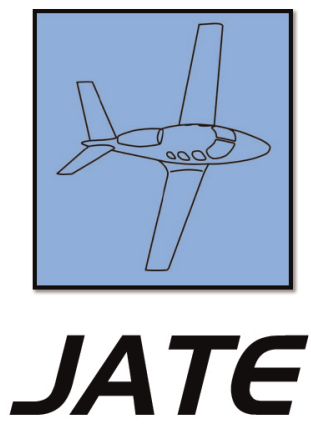

Journal of Aviation Technology and Engineering 1:1 (2011) 2-10

DOI: $10.5703 / 1288284314630$

\title{
Safety Risk Management, Assurance, and Promotion: A Hazard Management System for Budget-Constrained Airports ${ }^{1}$
}

\author{
Chien-tsung Lu, Stewart W. Schreckengast, and Jim Jia \\ Purdue University, West Lafayette, IN
}

\begin{abstract}
On October 7, 2010, the Federal Aviation Administration (FAA) issued a Notice of Proposed Rulemaking (NPRM) to extend Safety Management Systems (SMS) from airlines to certificated airports, including smaller FAR Part 139 Class IV airports (FAA, 2010). As the passage of the airport SMS rule is expected and could financially impact low-revenue airports, the purpose of this study is to develop a low-cost SMS for the airport community. This project was initiated in May 2010 and adopted ICAO Doc. 9859 SMM and FAA Advisory Circulars 150/5200-37 and 120-92 to design a computer-based hazard management system for airports. From open sources, several OnLine Analytic Processing (OLAP) data collection, mining, and mapping techniques were utilized, with Purdue University Airport (KLAF) as the testbed. The prototype was evaluated by students including pilots, technicians, managers, and traffic controllers. Most importantly, the prototype was developed with a minimum budget, and the final product can be utilized by any airport in the world to launch a safety management system. While the preliminary outcome of the prototype is significant, more advanced managerial features are anticipated based upon continuous multi-disciplinary synergy with airports and the FAA's financial support.
\end{abstract}

Keywords: SMS, airport safety, hazard control

\section{Introduction}

Airport safety has evolved over time from a reactive to a proactive and predictive model. The purpose of a proactive and predictive safety program is to detect hazards or threats and mitigate them before an accident occurs. In the U.S., Safety Management Systems (SMS) were introduced to the aviation industry in 2000 and are increasingly gaining recognition. The Airline Safety and Federal Aviation Administration Extension Act of 2010 was passed by the government in July 2010 and mandates that air carriers implement SMS. On October 7, 2010, the Federal Aviation Administration (FAA) proposed another Notice of Proposed Rulemaking (NPRM) to extend SMS from airlines to certificated airports, including 14 CFR 139 Class IV airports (low revenue airports), in the hope that a similar set of decision-making tools can be used to plan, manage, and direct business activities and enhance safety and ensure regulatory compliance.

\footnotetext{
${ }^{1}$ This project is sponsored by Purdue University Discovery Park.
} 
"As the certificate holder best understands its own operating environment, it is in the best position to address many of its own safety issues" (Safety Management System, 2005). The four essential pillars or components of an SMS program are safety policy (procedures and process controls), safety risk management (hazard recognition and assessment), safety assurance (data analysis and data-driven corrective actions), and safety promotion (prioritized trainings, information sharing, and communication) (FAA, 2006 \& 2007; ICAO, 2006). Pursuant to the proposed SMS Safety Risk Management NPRM and to address an airport's own safety issues, an appropriate starting point is an internal airport hazard reporting and management system, which could help with safety assurance and safety promotion. As a result, "SMS's proactive emphasis on hazard identification and mitigation, and on communication of safety issues, provides certificate holders robust tools to improve safety" (Safety Management System, 2005).

The FAA envisions that certificated airports must be able to

1. actively engage airport management in airfield safety;

2. proactively look for safety issues through analysis and use of lessons learned; and

3. train individuals accessing the airside environment on SMS and operational safety (Safety Management System, 2005).

\section{Statement of the Problem}

Some airports (Class IV or non-hub airports) operate under a constrained annual budget, and a mandatory airport SMS could impose a substantial financial burden on those airports' operations. A low-cost airport SMS application is therefore necessary. To help airport authorities be more proactive in promoting airport safety, the goal of this proposal is to create a low-cost computer prototype of a hazard management system for lower-volume budgetconstrained airports pursuant to the ICAO Safety Management Manual (ICAO, 2006), FAA Advisory Circular 120-92 (FAA, 2006), FAA Advisory Circular 150/5200-37 (FAA, 2007) (Appendix A), Lu-Bos-Caldwell (2007) SMS model (Appendix B), and the proposed 14 CFR 139 Subpart E.

\section{Significance of the Prototype}

There are hundreds of 14 CFR 139 Class IV airports but most operate under a low revenue status. These airports need assistance in designing an effective and low-cost SMS. The FAA states that a properly functioning airport SMS would help an airport ensure that

1. individuals are trained on the safety implications of working on the airside of the airport;

2. proactive hazard identification and analysis systems are in place;

3. data analysis, tracking, and reporting systems are available for trend analysis and for recording lessons learned; and

4. safety issues are communicated in a timely manner to all stakeholders (Safety Management System, 2005).

A low-cost hazard management system based on a datamining genome and on open source Online Analytical Process (OLAP) technologies can be created to meet the predetermined goals. If a safety reporting and management system is successful, a hazard warehouse can be ready for data mining and trend study. Data analyses could then help prevent airport disasters by identifying possible dangers, implementing safety measures (through education or training), and delivering safety information to employees as soon as possible. A computerized hazard management system is also capable of tracking and is paperless and environmentally-friendly. The system can be designed to be anonymous and confidential in nature, which encourages airport workers to report observed hazards, including their own mistakes. As there is currently no such low-cost system available to low-revenue airports in the U.S., this pilot project has the potential to significantly impact SMS systems at such airports.

\section{Research Methodology}

The SMS researchers applied an Action Research (AR) methodology throughout the study. AR methodology is a scientific approach in which the researchers immerse themselves in a research setting for evidence discovery.

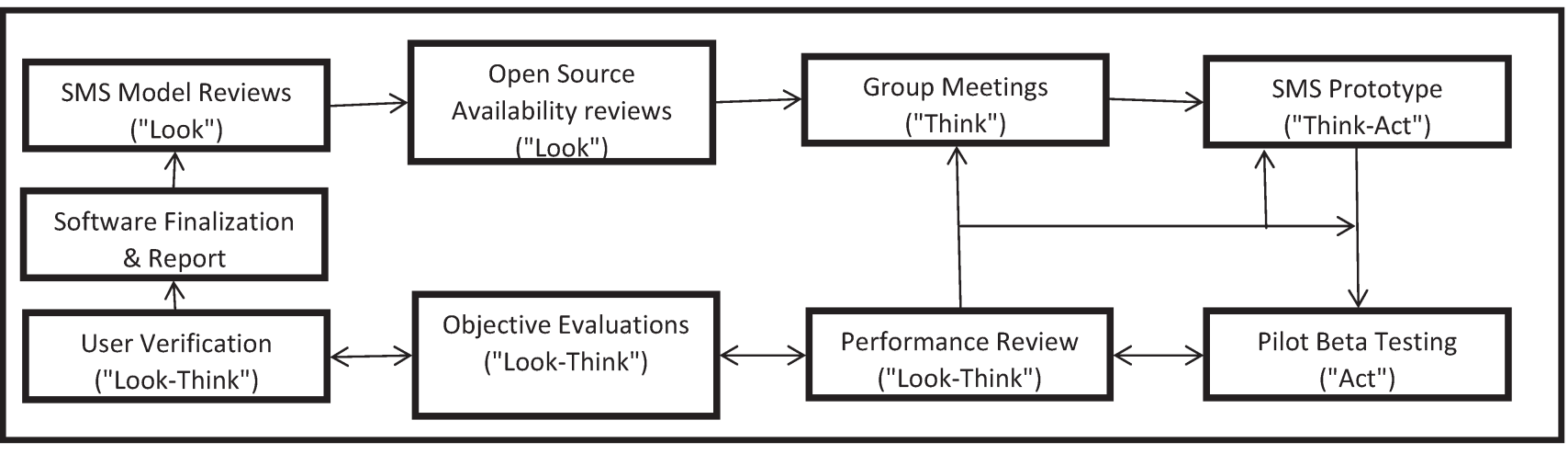


The researchers then experience first-hand the challenges, process cognition, and available knowledge, and are able to implement selected strategies (Reason \& Bradbury, 2001). Action Research procedures, also known as "Look-ThinkAct" loops, have been utilized in the qualitative research discipline for decades. A flow-chart is provided below.

The research began in early May of 2010. The timeframe of this study was conducted as follows:

1. May 2010: Review of the current FAA ACs 150/ 5200, 120-92 SMS, Lu-Bos-Caldwell model, ICAO Document No. 9859, and SMS-related materials from trade organizations.

2. June - July 2010: Inquiry regarding available open sources and assistance from software vendors, airport partners, Purdue systems, and the Purdue information technology department.

3. July 2010: Group meeting for system layout and plan.

4. July - September 2010: Design of the hazard management prototype including webpage interface, database, and algorithms for data mining activities.

5. October 2010 - November 2010: Pilot-testing of the system and performance review.

6. November 2010 - December 2010: Objective evaluation.

7. December 2010: User-verification and comments for finalizing the prototype.

\section{The Current Prototype}

The current hazard management system has the basic necessities in place for users to submit anonymous hazard reports and for administrators to review them in a timely fashion. On the user's side, the report submission interface is self-contained within a single preprocessor script and functions independently of the other modules. The user interface was designed to be intuitive to both airport employees and the general public using Dynamic HyperText Makeup Language (DHTML) techniques and feedback received during development (see Figure 1).

Aside from user-friendly Cascading Style Sheet (CSS) and tooltips, various client-side scripts are utilized to facilitate data entry. To serve a large user base, the submission page is compatible with most modern browser configurations such as Internet Explorer, Firefox, and Google Chrome. Because of the project's nature, the submission page is mission critical and is designed to be robust and flexible; an error in the administration modules will not influence the ability of users to successfully submit hazard reports. Currently, end user functions are

1. GIS using Google Map coordinate selections;

2. hazard type selections;

3. environmental factors (e.g., airport weather such as wind, rain, visibility, etc.);
4. hazard report narratives;

5. file attachment; and

6. confidential and anonymous reporting.

A benefit of the prototype is that it allows airport management to visualize deficiencies, prioritize them based upon hazard risk importance, assign resources, and archive corrected actions for regulatory oversight. Furthermore, when sufficient resources are unavailable, these deficiencies can be presented to the airport board for consideration, policy guidance, and resource allocation.

On the administration side, the prototype features a userdiscriminating secure login procedure for risk analysis, control, and tracking. Currently, the system allows the administrator to:

1. retrieve reports, emails, and display all hazards on an airport's configuration;

2. visually map critical areas (movement, non-movement, and landside) on airport's layout;

3. show archival hazard details using drop-down list;

4. download and edit selected hazard reports (individually or group) from a security-enhanced database;

5. archive reports using Microsoft Excel templates for FAA inspection, audit, and documentation; and

6. provide datasets for statistical analysis, identifying urgent safety priority, immediate recommendations and safety trainings (see Figures 2, 3 and 4).

A visual reference of the airport layout showing all critical "hot zones" is handy for safety management, hazard tracking, and worker safety training. The design philosophy of the administration module is more interdependent due to a central loader script but otherwise is similar to that of the submission page. As before, all technologies are available with few license restrictions and can be assembled on a minimal budget. These features will also streamline many of the administrative and oversight obligations under current 14 CFR 139.402 and 139.403 inspection programs conducted by the FAA Airport District Offices.

\section{Conclusion}

According to the Federal Register Vol. 75, No. 194, pages 62022 and 62023 (FAA, 2010), an approved Airport SMS must include components that address safety policy, safety risk management, safety assurance, and safety promotion. While there are documents and guidelines available from the FAA, ICAO, and other trade organizations for designing safety policy pursuant to 14 CFR 139.402 (a), this proposed prototype is ready to help airport operators satisfy paragraphs (b), (c), and (d) of Section 402 within a short period of time.

1. Safety Policy is a brief statement of management's support for SMS and the assignment of responsi- 
Date and Time

Date $[M M / D D / Y Y Y Y]$

24-Hour Local Time [HH:MM]:

\section{Decimal Coordinates (WGS84) :}

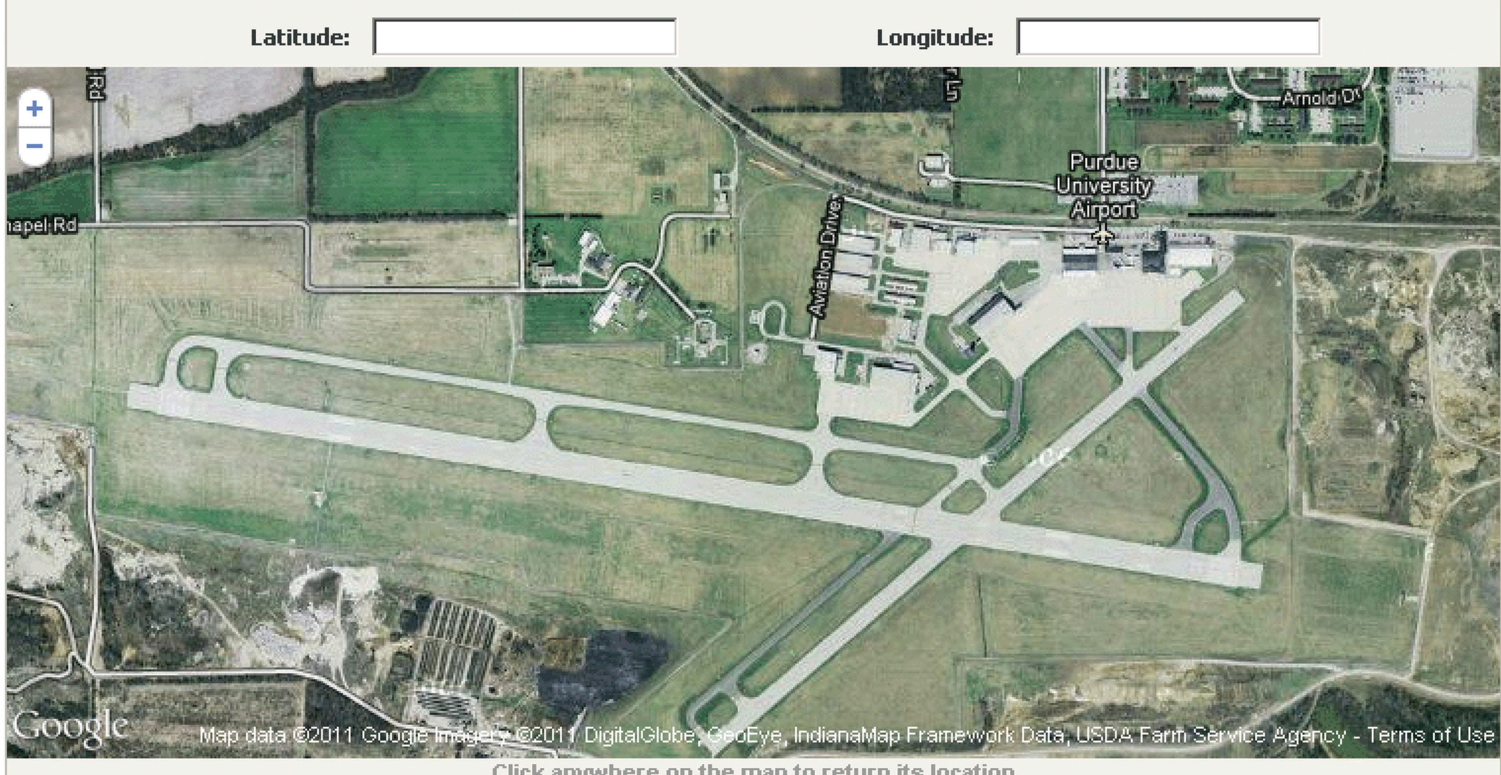

Click anywhere on the map to return its location

\begin{tabular}{rl|} 
Details & \\
\cline { 2 - 3 } & Select hazard type : \\
& Access Roads \\
& Aircraft issues \\
& ARFF \\
& ATC issues \\
& Construction \\
& Incursion/Excursion \\
& FOn \\
\hline \multirow{5}{*}{ Weather : } & Not Sure \\
& Clear \\
& Cloudy \\
& Raining \\
& Snowing \\
& Icing \\
\hline Other & Not Sure \\
Conditions: & None \\
& Fog \\
& Smog \\
& Thunderstorm \\
& Tornado \\
\hline
\end{tabular}

Selected Options :

Hazard Type:

Environmental Conditions:

Personal Observations :

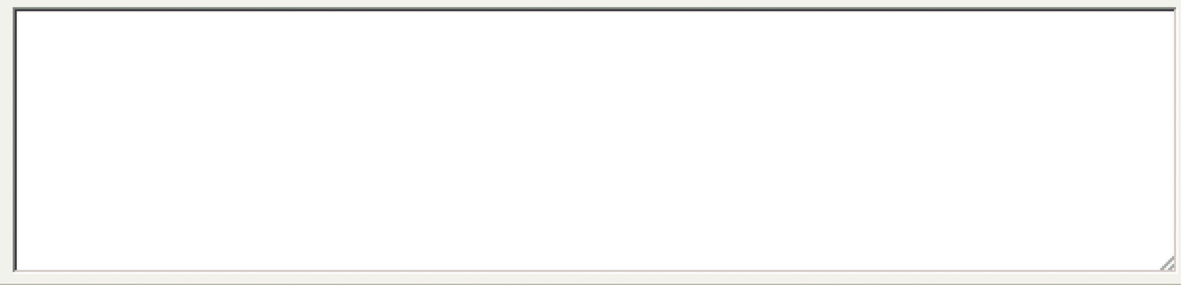

Attach a Photo - Optional

File to upload: Choose File No file chosen 


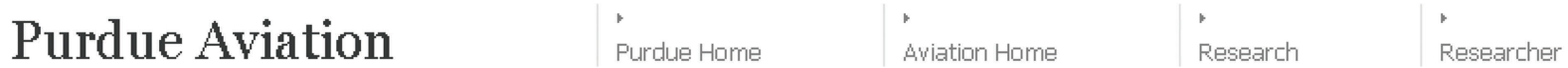

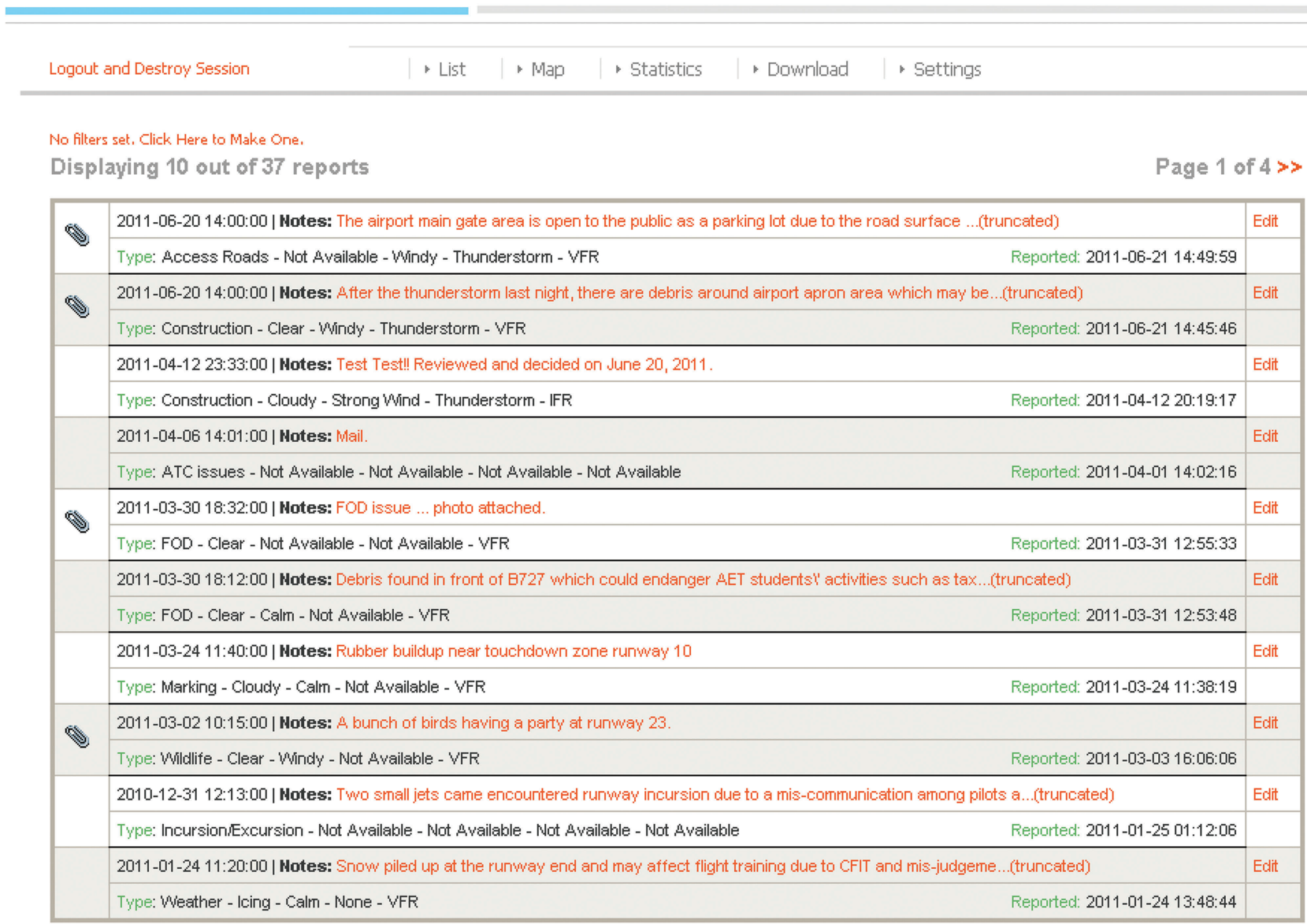

Figure 2. Administrative view of reported hazards and records.

bilities throughout the organization. There are several good examples of written safety policy in the FAA and ICAO references; however, it is critical that senior management strongly support these policies.

2. Safety Risk Management (SRM) provides the initial processes and procedures for identifying hazards and their associated risks within airport and for changes to those operations. This includes the establishment of a system to identify, analyze, set risk values, propose corrective (mitigating) action, and evaluate the results of that mitigation. Management must then determine if the mitigation is sufficient or if additional SRM is required. If the mitigation is sufficient for a prescribed period, then the process can graduate to the safety assurance component.

3. Safety Assurance (SA) provides processes and procedures to ensure mitigations developed through the airport's SRM are functioning effectively. Processes and procedures remain in the SA phase unless additional unresolved hazards are identified or significant changes in processes or procedures are initiated. For example, if a new air carrier or fixed- base-operator joined the airport, then the SRM process would have to be revalidated considering these new processes. In the mature SA component, there will still be minor hazards reported and mitigated. This open reporting culture should be promoted to ensure any new critical safety information is brought to the attention of management and given appropriate risk assessment and consideration for resolution.

4. Safety Promotion provides processes and procedures to foster an airport's safety environment and further encourages support of SMS. This process can start in the SRM component and expand and mature along with the implementation of SMS. Safety Promotion provides the foundation for SMS sustainability through formal safety training for airport and tenant employees, maintenance of safety awareness training for prescribed periods, and a platform for communicating SMS awareness. This dissemination of safety lessons learned and relevant successful resolution of safety risks further encourages employee involvement in hazard identification and mitigation. Some organi- 


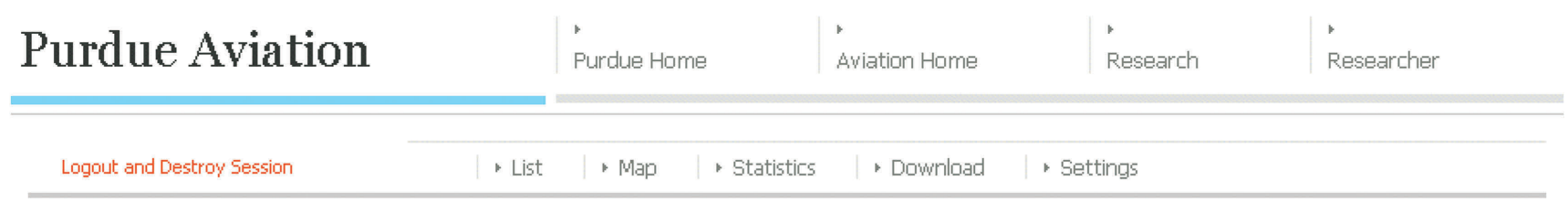

No filters set. Click Here to Make One.

Mapping all markers

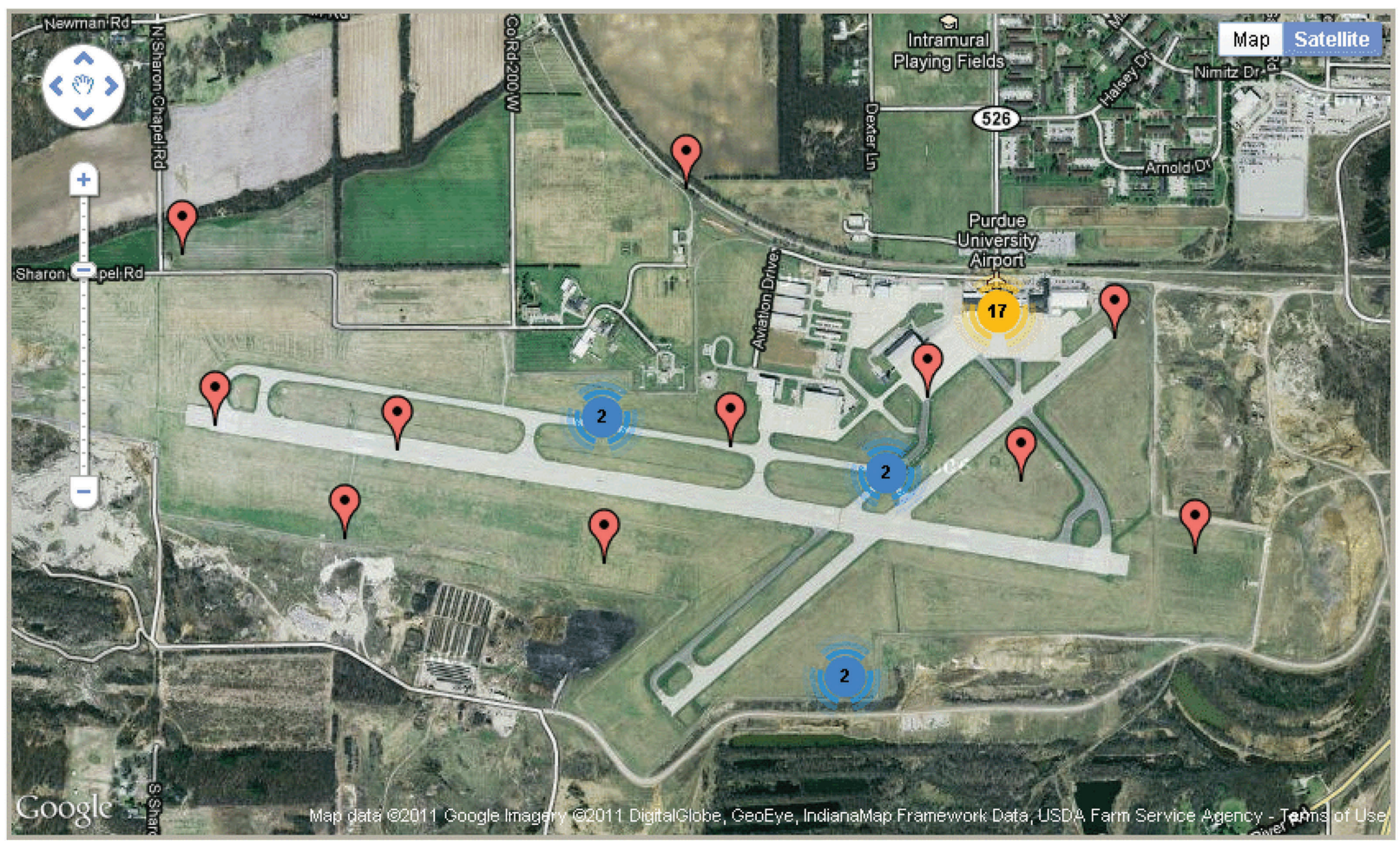

Figure 3. Administrative view using Google Maps visual hazard management.

zations provide a publication or website featuring safety articles, safety contributors, and even safety awards for individuals and groups.

The development of this process will be a function of the airport complexity, number of service providers, and resources; however, some of these functions normally exist at airports and should be incorporated into the SMS to minimize the impact and bridge between the old and new safety programs. The implementation schedule of SMS will be coordinated with the FAA Airport District Office.

With the above proposed rules in mind, this hazard reporting and management prototype is ready to be modified and tailored for an airport's usage regarding hazard detection, analysis, mitigation, tracking, archiving, and the FAA's audit, and is ready for immediate adoption to satisfy the proposed SMS rules.

\section{Follow-up Developments}

Although commenting on the NPRM Docket FAA-20100997 was extended to March 7th, 2011, currently there are unsolved concerns and questions from the airport industry including

1. how does FAR 139 certification process incorporate SMS components;

2. shortage of staff and funding and possible inexpensive alternations;

3. the lack of a cost-benefit analysis of the new regulation;

4. reliable models of risk calculation and hazard mitigation;

5. implementation process (phased-in or aggressive);

6. effective SMS training for employees;

7. lessons learned from pilot airports' SMS results; and

8. the collaboration and communication among ATC, air carriers, airports, and tenants under the SMS scope.

The current prototype framework for the hazard management prototype is complete and could be used by airports to manage hazards. However, there will be new features necessary to make this a professional product. Follow-up developments to be added in the future are: 


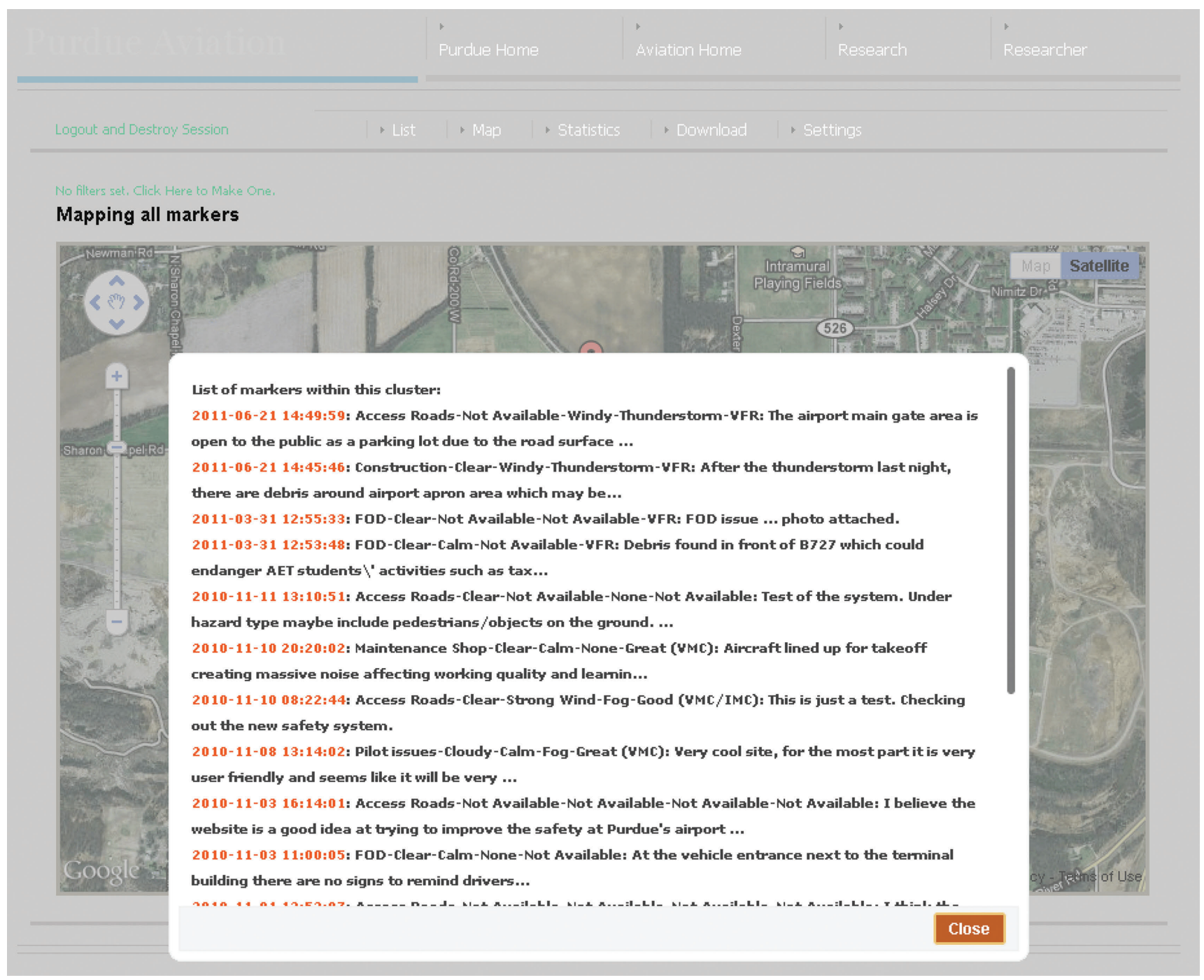

Figure 4. Administrative view drop-down list management.

1. Advanced SMS features: (1) Automatic tracking of hazards and providing hazard status and mitigation process using color-coded indications (green, yellow, and red, etc.); and (2) creating a managementoriented safety information distribution system.

2. Beta test: Soliciting additional voluntary airports (14 CFR 139 certificated airports) to utilize the prototype and provide comments for system improvements.

3. Content Management System (CMS): Configuration and user management are currently done by directly editing source code and databases, but those will eventually be migrated to a content management system (CMS). Using the CMS, administrators will be able to modify all relevant values and install additional features such as statistical analysis packages without a working knowledge of the source code. The prototype needs to be transitioned to a CMS format with a professional interface.

4. Mobile interface enhancements: In addition to CMS development, there are plans for user interface enhancements, including mobile versions (such as iPhone or Android) of the report submission page. Smart phones are popular with many airport employees and can be used to report airport hazards onsite immediately with video and photo attachments. While the current website is accessible to mobile users with JavaScript capability, user agent discrimination will allow different interfaces for different devices. On the administration side, users will have more choices of how the data is presented.

5. Industry-level database security: Enhancing database security is a must. The system administration will need to have access to full-text search and features that allow a control of which reports are listed. Also, the editing feature is needed so as to remove confidential information embedded in the hazard report, thereby protecting those who submit reports.

6. Statistical analysis: The statistical data analysis, automatic risk matrix calculation, and hazard alert features should be developed once the prototype's 
database is enriched after testing. This feature helps airport managers manage hazards effectively and efficiently.

7. System safety tools: This feature is an essential part of the prototype as data archive and hazard mitigation reports would ultimately be a part of an airport's record for various purposes. The hazard mitigation reports based on system safety tools (e.g., Job Safety Analysis or Preliminary Hazard Analysis) could be the basis of the mitigation tracking feature and be the foundation for "best practices" to share with the industry.

8. Installer package: In order to minimize the technical expertise needed to setup the system, an installer package and accompanying documentation will be required.

9. Financial analysis and budget development: Costeffect analysis is critical. This prototype aims to proactively monitor low level hazards and forecast when actions are required (e.g., pavement marking, replacement of runway fixtures, seasonal wildlife

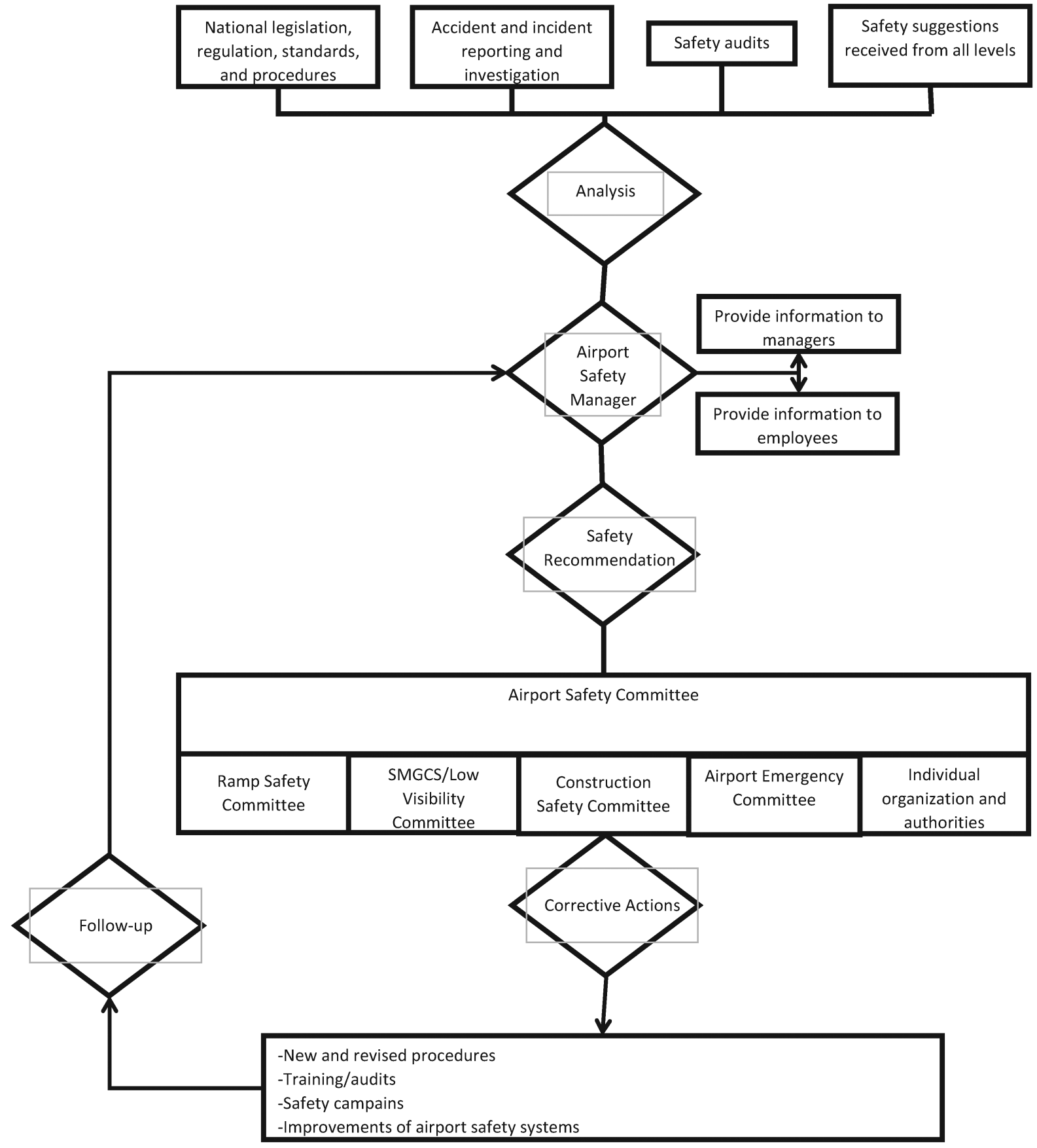

FAA AC 150/5200-37 SMS Life Cycle 


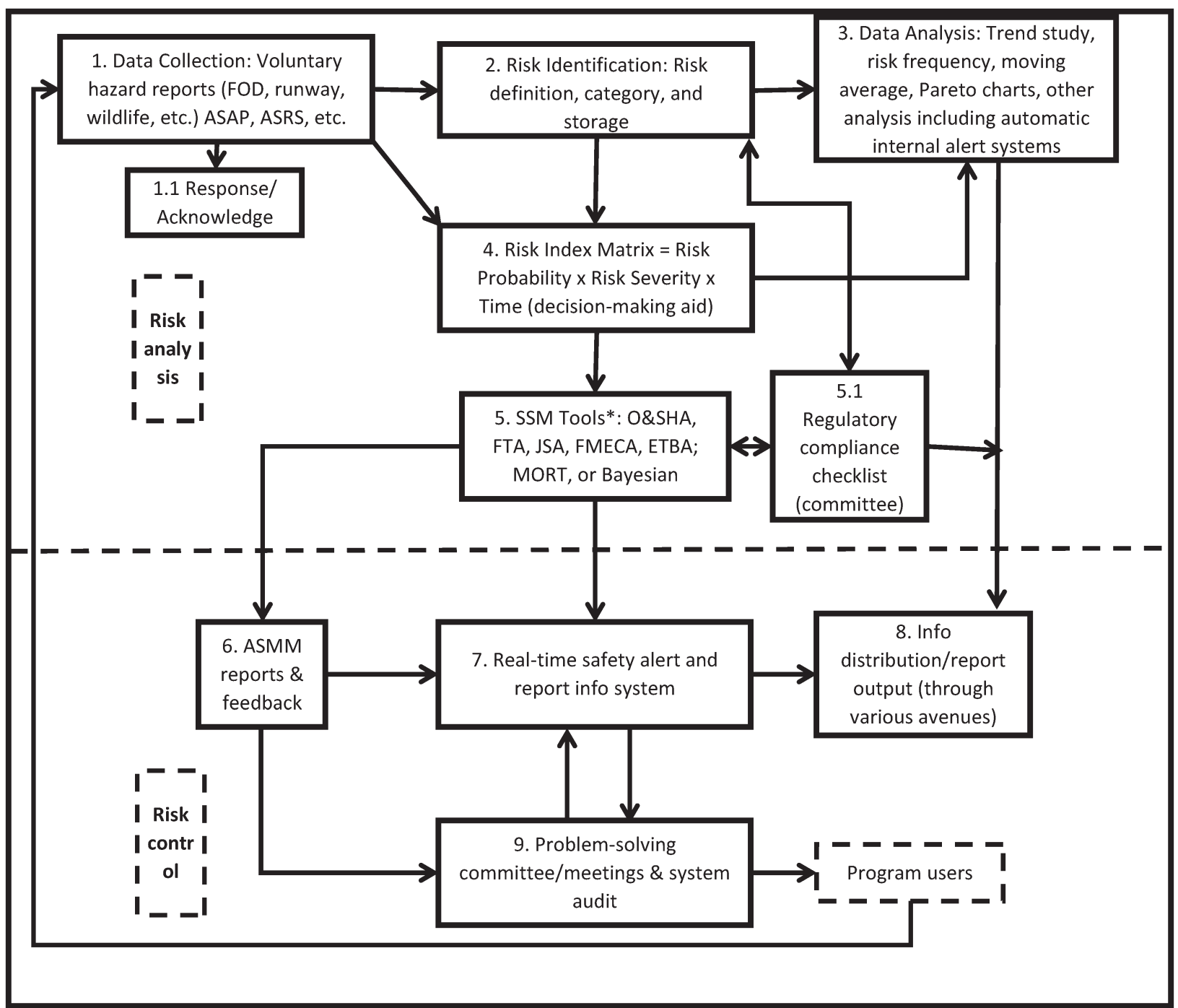

Lu-Bos-Caldwell Aviation Safety Management Model, AR's "Look-Think-Act" path

intrusions, etc.). This outcome of prototype implementation should also be the foundation upon which to establish budget and support grant requests.

\section{Appendix A}

Source: FAA AC 150/5200-37 Introduction of Safety Management Systems for Airport Operators

\section{Appendix B}

* O\&SHA: Operating \& Support Hazard Analysis; FTA: Fault Tree Analysis; JSA: Job Safety Analysis; FMECA: Failure Mode \& Effectiveness Criticality Analysis; ETBA: Energy Trace \& Barrier Analysis; MORT: Management Oversight \& Risk Tree.

\section{References}

Bowen, B., \& Lu, C-t. (2000). Advocating the implementation of an airline safety information system. Public Works Management \& Policy, 5(2), 91-96.

Federal Aviation Administration. (2006). Introduction to safety management systems for air operators (AC 120-92). Washington DC: Government Printing Office.

Federal Aviation Administration. (2007). Introduction to safety management systems for airport operators (AC 150/5200-37). Washington DC: Government Printing Office.

Safety management system for certificated airports; Extension of comment period, 75 Fed. Reg. 62008 (2010) (to be codified at 14 CFR 139).

International Civil Aviation Organization. (2006). Safety management manual (Document No. 9859). Montreal, Canada: International Civil Aviation Organization.

Lu, C-t., Bos, P., \& Caldwell, W. (2007). System safety application: Constructing a comprehensive aviation system safety management model (ASSMM). International Journal of Applied Aviation Studies, $7(1), 28-45$.

Reason, P., \& Bradbury, H. (2001). Action research: Participative inquiry and practice. New York, NY: Sage. 